\title{
Character evolution in heterotrophic euglenids
}

\author{
Brian S. Leander ${ }^{1,3, *}$, Richard E. Triemer ${ }^{2}$ and Mark A. Farmer ${ }^{1}$ \\ ${ }^{1}$ Center for Advanced Ultrastructural Research, 154 Barrow Hall, The University of Georgia, Athens, Georgia, \\ 30602, USA \\ 2 Department of Cell Biology and Neuroscience, Nelson Biological Laboratories, 604 Allison Road, Rutgers Uni- \\ versity, Piscataway, New Jersey, 08854, USA \\ ${ }^{3}$ Present address: Department of Botany, University of British Columbia, 3529-6270 University Boulevard, Van- \\ couver, BC, V6T-1Z4, Canada; Fax 604-822-6089; E-mail: bleander@ interchange.ubc.ca
}

Received: 25 June 2001. Accepted: 23 July 2001

This article attempts to describe the key morphological innovations associated with the evolutionary transitions between bacteriotrophy, eukaryotrophy, phototrophy, and osmotrophy in euglenids. Attention was focused on heterotrophic euglenids in an effort to establish a robust phylogenetic hypothesis for the group as a whole. We present a cladistic analysis of a large morphological data set from the following taxa: Petalomonas, Entosiphon, Lentomonas, Ploeotia, Dinema, Distigma, Rhabdomonas, Menoidium, Peranema, Urceolus, Eutreptia, and Euglena. The majority of the 37 characters and 97 states recognized were associated with the pellicle, the feeding apparatus, and the flagellar apparatus. In addition to having pellicle strips, Petalomonas cantuscygni possessed mitochondrial inclusions that were strikingly similar to the kinetoplasts found in kinetoplastids. Dinema sulcatum held a pivotal position in the phylogenetic tree and possessed many characters that bridged bacteriotrophic taxa with eukaryotrophic taxa. Distigmids and rhabdomonads formed a clade of osmotrophs that descended from eukaryotrophic ancestors, while Urceolus cyclostomus possessed a feeding apparatus, a putative photoreception apparatus and cytoskeletal features that clearly linked the phototrophs to eukaryotrophic ancestors. Evolutionary implications that emerged from these results were discussed.

Key words: Cladistics, Euglenozoa, Evolution, Morphology, Phylogeny.

\section{Introduction}

The Euglenida consists mostly of free-living flagellates with very diverse modes of nutrition. A number of heterotrophic euglenids (e.g., Petalomonas and Ploeotia) are limited to bacteriotrophy (Fig. 1a-c) while others (e.g., Dinema and Peranema) are capable of ingesting eukaryotic prey (Fig. 1f). We use the label "eukaryotroph" to distinguish the latter taxa from the bacteriotrophs (Triemer and Farmer 1991a; L eander and Farmer 2001b). $\mathrm{N}$ onetheless, the most obvious euglenids in field samples tend to be phototrophs (e.g., Euglena and

\footnotetext{
* corresponding author (see present address)
}

Phacus) (Fig. 1g) that have acquired plastids via secondary endosymbiosis (Gibbs 1978, 1981). 0 ther euglenids lack both plastids and the ability to phagocytize and are assumed to acquire their nutrients by absorbing organic molecules from the environment; collectively, these euglenids have been referred to as "osmotrophs".

Some osmotrophs (e.g., Astasia longa and $\mathrm{H}$ yalophacus) are clearly derived from a photosynthetic ancestor by the loss of plastids ( $\mathrm{G}$ ockel and $\mathrm{H}$ achtel 2000), an event that occurred multiple times (Linton et al. 2000; M üllner et al. 2001). By contrast, the phylogenetic position(s) of os- 
motrophs like distigmids and rhabdomonads (Fig. $1 d-e$ ) is less obvious; how ever, small subunit (18S) rD N A sequences indicate that they diverged prior to the eukaryotrophic Peranema and the phototrophs (Preisfeld et al. 2000, 2001; L eander and Farmer 2001b; M üllner et al. 2001). We are interested in identifying the key morphological innovations in euglenid evolution associated with the transitions between bacteriotrophy, eukaryotrophy, phototrophy, and osmotrophy, but it is first necessary to establish a robust phylogenetic hypothesis for euglenids as a whole.

M uch speculation about the evolutionary history of euglenids has occurred in the last four decades. Figure 2 illustrates the progression of thought regarding the phylogenetic relationships of taxa possessing the four primary modes of nutrition. When the distinction was not made in the literature, "phagotroph" refers to bacteriotrophs and eukaryotrophs collectively; we refer only to distigmids and rhabdomonads sensu lato (L eedale and Hibberd 1974; Cann 1986; Preisfeld et al. 2001) (Fig. 1d-e) as "osmotrophs" and not to those taxa that are clearly derived from phototrophs.

Prior to the widespread acceptance of the Serial Endosymbiotic Theory (SET), Leedale (1967) posited that the ancestral euglenid was a phototroph similar to the biflagellates Eutreptia and Eutreptiella and that osmotrophic and most bacteriotrophic euglenids shared a heterotrophic common ancestor that was similar to the colorless $D$ istigma (Fig. 2a). H owever, the bacteriotroph E ntosiphon was considered more closely related to eukaryotrophic euglenids. L eedale left the relationships between extant phototrophs, eukaryotrophs, and the group consisting of osmotrophs and bacteriotrophs unresolved (Fig. 2a).

D uring the following decade, the SE T gained acceptance, and L eedale (1978) revised his scheme by suggesting that the ancestral euglenid was an osmotroph similar to D istigma, and the subsequent origin of phagotrophy united the bacteriotrophs, eukaryotrophs, and phototrophs (Fig. 2b). L eedale (1978) also accounted for the possibility that the phototrophs were derived from a phagotrophic ancestor that acquired plastids via endosymbiosis.

In the 1980's and early 1990's, the close relationship between bodonid kinetoplastids and euglenids became very clear, and many authors suggested that the ancestral euglenid was a phagotroph (Willey et al. 1988) (Fig. 2c). Willey and Wibel (1985b) reasoned that bacteriotrophic eu- glenids with a simple feeding pocket, like Petalomonas, were more closely related to phototrophs than to eukaryotrophs and Entosiphon, which have a complex feeding apparatus comprised of rods and vanes (Fig. 2C). D awson and Walne (1994) modified the argument by emphasizing the putative phylogenetic position(s) of osmotrophs. These authors suggested graphically that (1) osmotrophs and phototrophs are united by the loss of phagotrophy yet (2) plastids were subsequently gained in the phototrophic lineage (Fig. 2C). H owever, they contradictorily supported the notion that euglenid plastids originated from a phagotrophic ancestor (D awson and Walne 1994).

$\mathrm{H}$ istorically, phylogenetic hypotheses of euglenids have been based on intuition and an emphasis on a few morphological features. D uring the last decade, however, a great deal of information has accumulated for heterotrophic euglenids (Triemer 1986, 1988; Triemer and Fritz 1987, 1988; Farmer and Triemer 1988a, 1988b, 1994; Triemer and F armer 1991a; 1991b; Belhadri and Brugerolle 1992; Belhadri et al. 1992; Linton and Triemer 1999, 2001; L eander and Farmer 2001a) that permits us to cladistically analyze their phylogenetic relationships in the context of a large ultrastructural data set. In this vein, we report new data on the ultrastructure of two Petal omonas taxa, D inema sulcatum, D istigma proteus, M enoidium cultelIus, R habdomonas incurva and U rceolus cyclostomus. $M$ any morphological characters associated with the euglenid pellicle were identified in previous studies that evaluated the relationships among phototrophic euglenids (Leander and Farmer 2000a, 2000b, 2001a, 2001b). In this article, we expand the data matrix by identifying a number of characters and states associated with the flagellar and feeding apparatus. $\mathrm{O}$ ur phylogenetic analyses support the hypothesis illustrated in Figure $2 d$, which clarifies many ambiguities present in the hypotheses outlined previously. Brief introductions to the three principal sources of morphological variation within heterotrophic euglenids follow.

\section{Euglenid pellicle}

The cy toskeleton or "pellicle" of euglenids consists of four main components: (1) the plasma membrane, (2) proteinaceous strips, (3) microtubules, and (4) tubular cisternae of endoplasmic reticulum (L eander and Farmer 2000a, 2001a). The morphological diversity found in the strips makes 
them the most significant components from the perspectives of phylogeny and taxonomy. They are positioned immediately below the plasma membrane, run in parallel along the anteroposterior axis of the cell, articulate along their lateral borders, and may be arranged either helically or longitudinally (Triemer and Farmer 1991b; Leander and Farmer 2000a, 2001a). A t the anterior end of many taxa, the strips line the canal and eventually terminate near the reservoir (Leander and Farmer 2000a). Strips may differ between taxa in how they are organized around the surface of the cell and in substructural details (L eander and F armer 2000a, 2000b, 2001a, 2001b). Future characterization of differences in the organization of pellicular microtubules may also proveinformative.

\section{Flagellar apparatus}

The basic organization and structure of the flagellar apparatus in euglenids is very similar to that of bodonids and diplonemids (Simpson 1997). There are usually two functional basal bodies designated "dorsal" and "ventral" that are associated with three flagellar roots (Surek and M elkonian 1986). The "intermediate" and "ventral" roots are associated with the ventral basal body, the dorsal root is associated with the dorsal basal body. A "striated fiber" (syn. basal body connective, Solomon et al. 1987) usually extends between the two basal bodies (Triemer and Farmer 1991b). The microtubules of the intermediate and dorsal roots are linked to bands of microtubules that support the canal and pellicle (syn. "dorsal pellicular microtubule band" - Surek and M elkonian 1986). The two flagella are designated as either "dorsal" (syn. anterior) or "ventral" (syn. posterior or recurrent) depending on the basal body from which they stem and are usually each supported by paraxial rods that differ slightly in structure (D awson and Walne 1994; Simpson 1997). The flagellar apparatus may differ between taxa in the relative lengths of the flagella, in details of the flagellar transition zone, and in flagellar beat pattern. In addition, some taxa possess a photosensory "paraflagellar swelling" at the base of the dorsal flagellum (K uźnicki et al. 1990).

\section{Feeding apparatus}

With respect to euglenozoans, eukaryotrophy occurs only within the Euglenida and is facilitated, in part, by a specialized feeding apparatus of "rods" and "vanes" (Triemer and Farmer 1991b). A feeding apparatus of this kind is al so found in a number of bacteriotrophic euglenids (i.e., Entosiphon and Ploeotia) and a single rod-like structure (syn. nemadesm) is present in some bodonids ( $\mathrm{H}$ itchen 1974; Burzell 1975; Eyden 1977). The rods of euglenids are supported by amorphous material and microtubules that extend posteriorly from a discrete cytostome positioned near the canal opening (Triemer and Farmer 1991b). The lumen of the feeding apparatus and canal opening may merge into a common space called the "vestibulum", but an anterior "comb" or "cap" usually covers the opening of the cytostome. When the feeding apparatus protrudes from the vestibulum during feeding, the anterior cap moves to one side of the cytostome and consequently closes off the flagellar pocket ( $\mathrm{N}$ isbet 1974; Triemer and Fritz 1987). In most phagotrophic euglenids, the rods are closely associated with a "diaphragm-like" set of plicate folds or vanes that surround the cytostome (Triemer and Farmer 1991a, 1991b). A s prey is engulfed, the vanes rotate open in a pinwheel-like fashion (Triemer and F ritz 1987).

All bodonids (e.g., Bodo caudatus) and some bacteriotrophic euglenids (e.g., Petalomonas) lack rods and vanes altogether and phagocytize with a simple pocket lined on one side with microtubules, an apparatus called the "MTR" (Brooker 1971; Brugerolle et al. 1979; Triemer and Farmer 1991a). M TR-like structures have been found in a variety of phototrophic euglenids, which implies that they are derived from bacteriotrophic ancestors (Willey and Wibel 1985a, 1985b; Surek and Melkonian 1986; O wens et al. 1988). Current evidence suggests that the M TR is not homologous to the more complex feeding apparatus of rods and vanes as both kinds of apparatus can occur within the same cell (e.g., D inema) (Farmer and Triemer 1988a; Triemer and O tt 1990; Triemer and Farmer 1991a); in these cases, the MTR is assumed to be vestigial or to function in pinocytosis as it does in trypanosomatids (Preston 1969; Brooker 1971; L om et al. 1980). T hus, there appear to be two unrelated types of feeding apparatuses: the MTR and the rod-and-vane-based apparatus.

The feeding apparatus may differ between taxa in the number of rods (e.g., 0,2 or 3), the relative number of microtubules in the rods, the length of the rods relative to the length of the cell, the number of vanes (e.g., 4 or 5), and the presence of a phagocytic M TR. 


\section{Material and methods}

\section{Study organisms and culture conditions}

The 21 taxa examined in this study, their locations either in the field or in culture collections, and the references used to score specific character states are listed in Table 1. Petalomonas cantuscygni was grown in an A SWP (A rtificial Seawater for Protozoa) medium (http:// ww w.ife.ac.uk/ccap/mediarecipes.html \#asw p). D istigma proteus, $R$ habdomonas incurva, R . costata, and M enoidium cultellus were grown in soil/water medium enriched with crushed barley (1 grain/200 ml) (Starr and Zeikus 1993). Peranema trichophorum was grown in a Peranema medium (PER, The Culture Collection of A lgae and Protozoa, A mbleside, Cumbria, UK) containing "Complan" (H. J. H einz C O. L td., H ayes Park, Middlesex, UK). Eutreptia pertyi, Euglena acus, E. laciniata, E. terricola and Lepocinclis buetschlii were grown in a soil/water $\left(\mathrm{Gr}+/ \mathrm{NH}_{4}\right)$ medium enriched with calcium carbonate $(0.1 \mathrm{~g} / 200 \mathrm{ml})$ and ammonium magnesium phosphate hexahydrate $(0.1 \mathrm{~g} / 200 \mathrm{ml})$ (Starr and Zeikus 1993). E uglena mutabilis was grown in equal parts of Euglena medium (EG, Greenblatt and Schiff
1959) and soil water extract. The cultured taxa were grown at $20{ }^{\circ} \mathrm{C}$ and $12: 12 \mathrm{~L}: \mathrm{D}$ cycle; all other taxa in the analysis were isolated from the field (Table 1).

\section{Electron microscopy}

C ells of D . proteus, E . pertyi, E . acus, E. laciniata, E. mutabilis, E. terricola, L. buetschlii, M. cultellus, P. trichophorum, R. costata, and R. incurva were prepared for scanning and transmission electron microscopy (SEM and TEM, respectively) using the protocols described by L eander and Farmer (2000a, 2001a). C ells of D. sulcatum, E. sulcatum, L. applanatum, P. cantuscygni, P. mediocanellata, P. costata, P. vitrea, and U . cyclostomas were prepared for SEM and TEM by the protocols described in Triemer $(1985,1986)$ and Farmer and Triemer (1988a). SEM data were presented on a black background using A dobe Photoshop 5.0.

\section{Phylogenetic analysis}

$\mathrm{N}$ inety-seven character states within 37 morphological characters were recognized and scored for 19 euglenid taxa and two kinetoplastid taxa (Tables 2 and 3 ).

Table 1. The taxa examined in this study.

\begin{tabular}{|c|c|c|}
\hline Taxon & Source ${ }^{a}$ & R eferences \\
\hline Bodo saltans & - & Brooker 1971; Vickerman 1991 \\
\hline Bodo caudatus & - & Brooker 1971; Vickerman 1991 \\
\hline Petalomonas mediocanellata & Field & F armer and Triemer 1988a; Triemer and Farmer 1991b \\
\hline Petalomonas cantuscygni & CCAP $1259 / 1$ & F armer and Triemer 1988a; Triemer and F armer $1991 b$ \\
\hline Entosiphon sulcatum & Field & $\begin{array}{l}\text { Triemer and F ritz 1987; Triemer and F armer 1991b; } \\
\text { Belhadri et al. } 1992\end{array}$ \\
\hline L entomonasapplanatum & Field & Triemer and F armer 1991b; F armer and Triemer 1994 \\
\hline Ploeotia costata & Field & $\begin{array}{l}\text { Triemer 1986; F armer and Triemer 1988a; } \\
\text { Triemer and F armer 1991b; L inton and Triemer 1999, } 2001\end{array}$ \\
\hline Ploeotia vitrea & Field & F armer and Triemer 1988a; Triemer and Farmer 1991b \\
\hline R habdomonas costata & UTEX LB 1278 & L eedale and H ibberd 1974 \\
\hline Rhabdomonasincurva & UTEX LB 573 & - \\
\hline M enoidium cultellus & UTEX LB 528 & L eedale and H ibberd 1974 (M . bibacillatum) \\
\hline D istigma proteus & UTEX LB 508 & L eander and F armer 2000a, 2001b \\
\hline D inema sulcatum & Field & Triemer and F armer 1991b \\
\hline Peranema trichophorum & CBSC WW-13-1838 & $\begin{array}{l}\text { N isbet 1974; H ilenski and Walne 1885a; } \\
\text { Triemer and F armer 1991b; B elhadri et al. 1992; } \\
\text { L eander and F armer 2001b }\end{array}$ \\
\hline U rceolus cyclostomus & Field & Triemer and F armer 1991b \\
\hline E utreptia pertyi & UTEX 1290 & L eander and F armer (unpublished) \\
\hline Euglena mutabilis & SA G $1224-9 a$ & L eander and F armer 2000a \\
\hline Euglena laciniata & UTEX LB 1312 & L eander and F armer (unpublished) \\
\hline Euglena terricola & UTEX LB 1310 & L eander and F armer (unpublished) \\
\hline Euglena acus & UTEX LB 1316 & L eander and F armer 2001b \\
\hline L epocindisbuetschlii & UTEX LB 523 & L eander and F armer (unpublished) \\
\hline
\end{tabular}

${ }^{a}$ C BSC , C arolina Biological Supply C ompany, Burlington, N C; C C A P, C ulture C ollection of A lgae and Protozoa, C umbria, U .K .; SA G , Sammlung von A Igenkulturen G öttingen; U TEX , C ulture C ollection of A lgae at the U niversity of Texas, A ustin, TX. 
Table 2. Thirty-seven morphological characters and 97 states associated with the pellicle, feeding apparatus, and flagellar apparatus of euglenids.

\section{C haracter}

1) Strips

2) 0 rientation of strips

3) Strips lining the canal

4) $P$ a

5) $W_{A}{ }^{b}$

6) Posterior strip reduction

7) Pattern of posterior strip reduction

8) $W_{P}{ }^{d}$

9) Binary pattern of pores

10) Cell plasticity

11) Transverse shape of cell

12) Frames

13) $O$ verhang

14) Prearticular projections

15) Postarticular projections

16) D oublet identity

17) A rch width : heel width

18) A rticulation zones bifurcatef

19) Flagellar strip

20) Fused frames $w /$ discontinuities

21) Supporting elements around canal

22) L ength of ventral flagellum

23) Ventral flagellum emergent

24) D orsal flagellar beat pattern

25) Paraflagellar swelling

26) Flagellar transition zone

27) Phagotrophic M TR

28) A nterior feeding cap/comb

29) Feeding apparatus: rods

30) Feeding apparatus: vanes

31) Rel. \# of microtubules in rods

32) Rod length : cell length

33) M ode of nutrition

34) Plastid morphology

35) $L$ arge paramylon grains

36) M itochondrial inclusion bodies

37) $C$ ell length 9

\section{Character States}

0 , absent; 1 , present

0 , longitudinal; 1 , helical

0 , absent; 1 , present

$0,5-8 ; 1,10-12 ; 2,14 ; 3,18-20 ; 4,28-32 ; 5, \geq 38$

0,$0 ; 1,1$

0 , absent; 1 , present

0 , partial $;$; , linear/pseudolinear; 2 , exponential

0,$1 ; 1,2 ; 2,3$

0 , absent; 1 , present

0 , rigid; 1 , plastic

0 , ovoid; 1 , circular; 2 , pentagonal; 3 , flat

0 , thin; 1 , robust

0 , absent; 1 , present

0 , absent; 1 , delicate; 2 , thread-like; 3 , tooth-like

0 , absent; 1 , indented plate

0 , absent; 1 , heels, 2 , arches; 3 , trough $\&$ flat

0 , indistinguishable; 1 , arches $\approx 3 X$ heele; 2 , arches $\geq 15 X$ heel;

3 , arches $\approx$ heels; 4 , arches $\approx 5 X$ heels; 5 , heel $\geq 3 X$ arches

0 , absent; 1 , present

0 , absent; 1 , present

0 , absent; 1 , present

0 , absent; 1 , present

$0, \geq 2 X$ cell length; $1,<2 X$ cell length

0 , present; 1 , absent

0 , whiplike/power-recovery stroke; 1 , held straight with twitching at tip;

2 , highly mobile; 3 , figure eight/lasso

0 , absent; 1 , present

0 , internal elements; 1 , hollow

0 , present; 1 , absent

0 , absent; 1 , present

0 , absent; 1,$2 ; 2,3$

0 , absent; 1,5 vanes - plicate; 2,4 vanes

0 , few; 1, many

$0,1: 1 ; 1, \leq 0.5: 1$

0 , bacteriotroph; 1, eukary otrophy; 2, osmotrophy; 3 , phototrophy

0 , shield; 1 , stellate; 2 , discoidal

0 , absent; 1 , present

0 , present; 1 , absent

$0,<20 \mu \mathrm{m} ; 1, \geq 20 \mu \mathrm{m}$

a " $P$ " refers to the maximum number of strips around the cell periphery (L eander and Farmer 2000a).

$\mathrm{b}$ " $\mathrm{W}_{\mathrm{A}}$ " refers to the number of anterior whorls of exponential strip reduction (L eander and F armer 2000a).

"Strips at the posterior end converge on a common line; most of the strips (e.g., 41 of 50) terminate on one side of the line and show an alternate pattern of strip reduction (L eander and F armer 2002).

$d$ " $W$ " refers to the number of posterior whorls of exponential strip reduction excluding primed Roman numerals (L eander and Farmer 2000a, 2000b).

e In D inema, scored from the six strips near the flagellar strip.

$f$ "Bifurcate" refers to a raised articulation zone bordered by a pronounced keel and overhang (e.g., Farmer and Triemer 1994).

${ }_{9}^{9}$ Scored from relaxed cells. 
The matrix of unordered character states was analyzed parsimoniously using the branch-and-bound algorithm and the default settings in PA U P* 4.0 (Sw offord 1999). Two bodonids, Bodo saltans and B. caudatus, were designated as the outgroup based on previous studies on the molecular phylogeny and comparative morphology of euglenozoans (Willey et al. 1988; Triemer and Farmer 1991a, 1991b; M ontegut-F elkner and Triemer 1997; Linton et al. 2000; Preisfeld et al. 2000, 2001). The support of the data for each node on the most parsimonious tree(s) was estimated using decay indices using A utodecay 4.0.2 (E riksson 1998) and nonparametric bootstrap percentages (Felsenstein 1985) from 500 replications using PA U P* 4.0. M acC lade 3.03 was used to phylogenetically map character state changes.

\section{Results}

\section{Comparative morphology of heterotrophic euglenids}

Tables 2 and 3 summarize the character states present in the taxa examined in this study. The descriptions in this section will be restricted to select- ed ultrastructural features of P. mediocanellata, P. cantuscygni, D. sulcatum, P. trichophorum, R. incurva, D. proteus, and U. cyclostomus. U Itrastructural features of Entosiphon, Ploeotia, Lentomonas, and the phototrophic taxa have been described in depth elsewhere (Triemer 1986, 1988; Triemer and Fritz 1987, 1988; Farmer and Triemer 1988a, 1988b, 1994; Triemer and Farmer 1991a, 1991b; Belhadri and Brugerolle 1992; Belhadri et al. 1992; Linton and Triemer 1999, 2001; Leander and F armer 2000a, 2001a, 2001b).

Both P. mediocanellata and P. cantuscygni are small bacteriotrophs possessing a dorsal flagellum that beats by rapidly twitching the distal end ( $\mathrm{C}$ ann and Pennick 1986). Petalomonas mediocanellata possessed a very short ventral flagellum that emerged from the vestibulum (Fig. 1a), whereas P. cantuscygni lacked one entirely (Fig. 1b). The pellicle of P. cantuscygni consisted of eight longitudinal strips that were more or less fused at the articulation zones (Fig. $1 \mathrm{~b}$ and 3); however, P. mediocanellata appeared to lack a pellicle of proteinaceous strips altogether (Fig. 1a; Farmer and Triemer 1988a). Both

Table 3. M atrix of 37 morphological characters for 21 taxa used in the parsimony analysis to infer phylogenetic relationships. All characters are unordered and equal in weight. The symbols for the characters and character states are defined in Table 2. N = unknown and dashes denote inapplicable characters.

Character

1111111111222222222233333333

Taxon 1234567890123456789012345678901234567

Bodo saltans

Bodo caudatus

Petalomonas mediocanellata

Petalomonas cantuscygni

Entosiphon sulcatum

L entomonas applanatum

Ploeotia costata

Ploeotia vitrea

Rhabdomonas costata

Rhabdomonasincurva

M enoidium cultellus

D istigma proteus

D inema sulcatum

Peranema trichophorum

U rceolus cycl ostomus

Eutreptia pertyi

Euglena mutabilis

Euglena laciniata

Euglena terricola

Euglena acus

L epocindis buetschlii
$0 \ldots 0 \ldots \ldots 00 \ldots 0000000000 \ldots 0-000$

$0-0 \ldots \ldots-\ldots 00 \ldots-\ldots 0000000000 \ldots-\ldots-000$

$0-0--0 \ldots-000 \ldots \ldots 00101000000-\ldots 0-000$

$1000-0--0000000000000001111010000--0-000$

$1001-0--0000000110000001001122100-010$

$1001-0--000010002100000100111120000-010$

$1001-0--00201010022210000001100111110000-010$

$1001-0--00000100002110000010011110000-010$

$1002-0--0010-003--0111122011-00--2-111$

$1002-0--0010-003--0111112011-00--2-110$

$1003-0--0030-000--0111112011-00--2-111$

$1103-0--0110100030001102011-00--2-111$

$1103-0--011000000101001010111122101-110$

$1115010-0110100003010110110111122111-111$

$111501 N N 0110100050000111111012111-111$

$11150110001101000030000102111-000-$ - 301111

$1115011110110111003000011-111-00--30111$

$111511211110121030000113111-000--31111$

$111511221111012103300001133111-000--31111$

$111441121001111310440000113111-00--32111$

$111411210111131040000113111-00--32111$ 


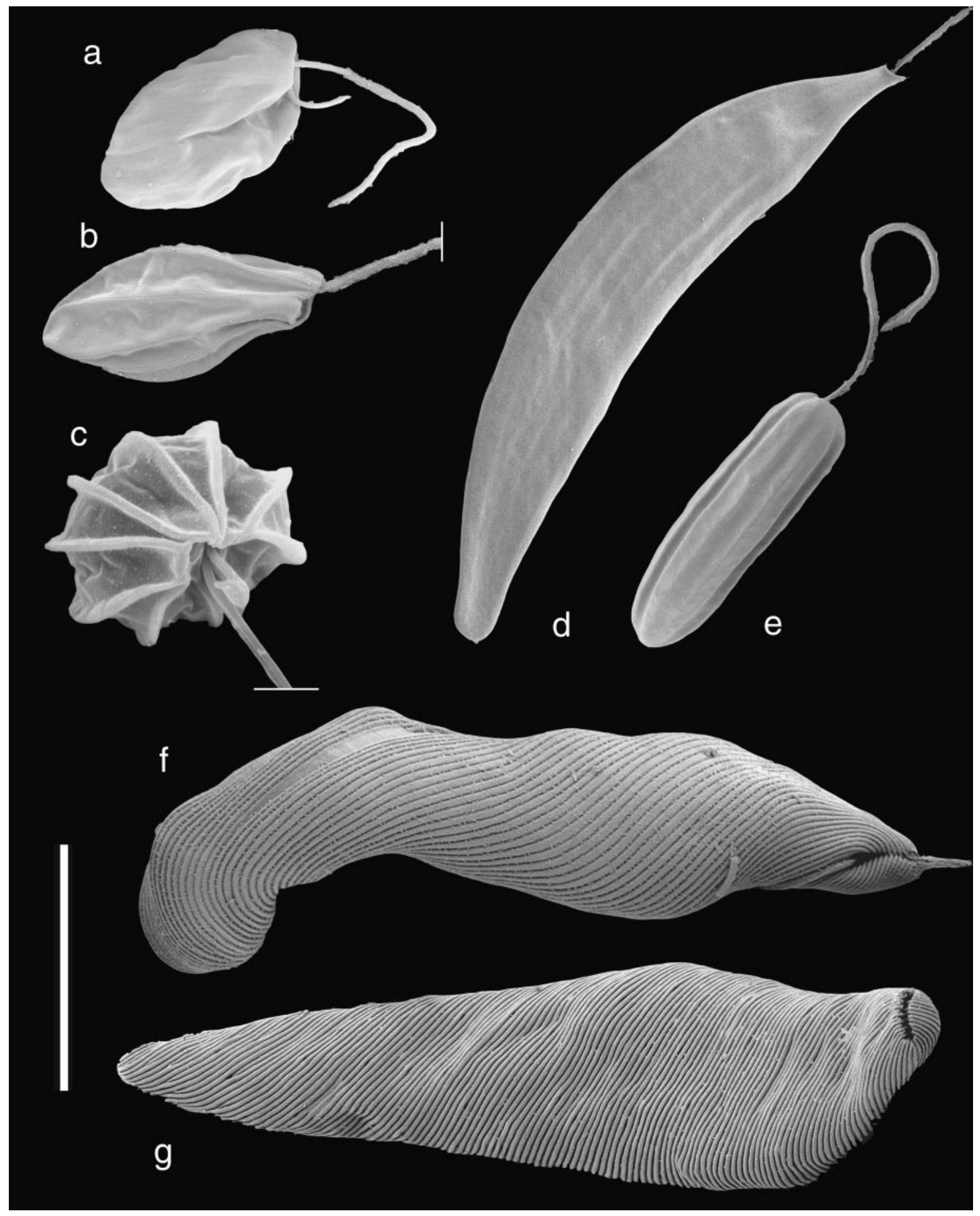

Fig. 1. Scanning electron micrographs (SEM) of some of the investigated taxa showing diversity in pellicle morphology and cell size (Bar $=10 \mu \mathrm{m})$. a. Petalomonas mediocanellata (bacteriotroph). b. Petalomonas cantuscygni (bacteriotroph). c. Ploeotia vitrea (bacteriotroph). d. M enoidium cultellus (osmotroph). e R habdomonas incurva (osmotroph). f. Peranema trichophorum (eukaryotroph). g. Euglena mutabilis (phototroph). 
P. mediocanellata and P. cantuscygni possessed mitochondrial inclusion bodies that were similar in appearance to kinetoplasts; the inclusions had an ordered nature to them and were centrally located in a portion of the mitochondrion that lacked cristae (Fig. 3 and 4). Like kinetoplasts, these inclusion bodies were found only in mitochondrial profiles positioned near the flagellar basal bodies.

D inema sulcatum, P. trichophorum, and U . cyclostomus are eukaryotrophs possessing plastic

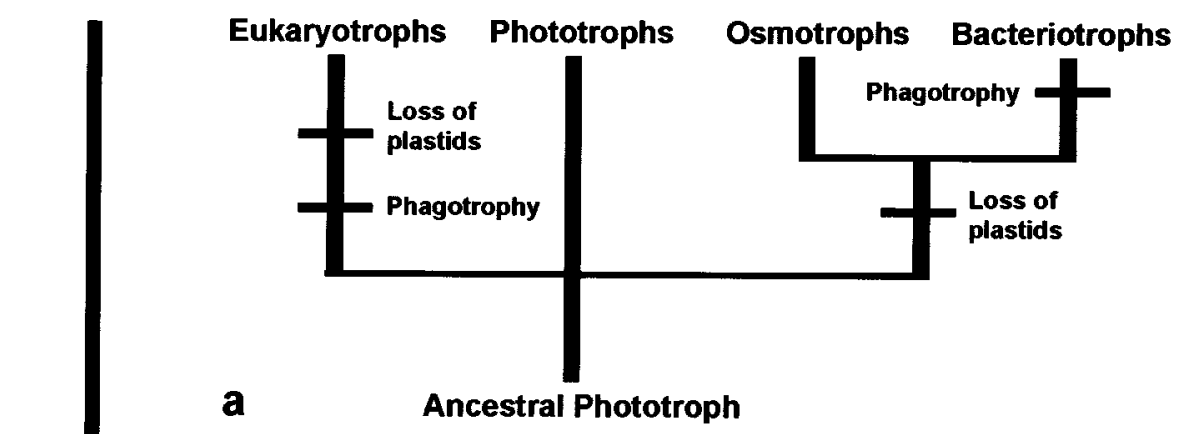

b

Ancestral Osmotroph
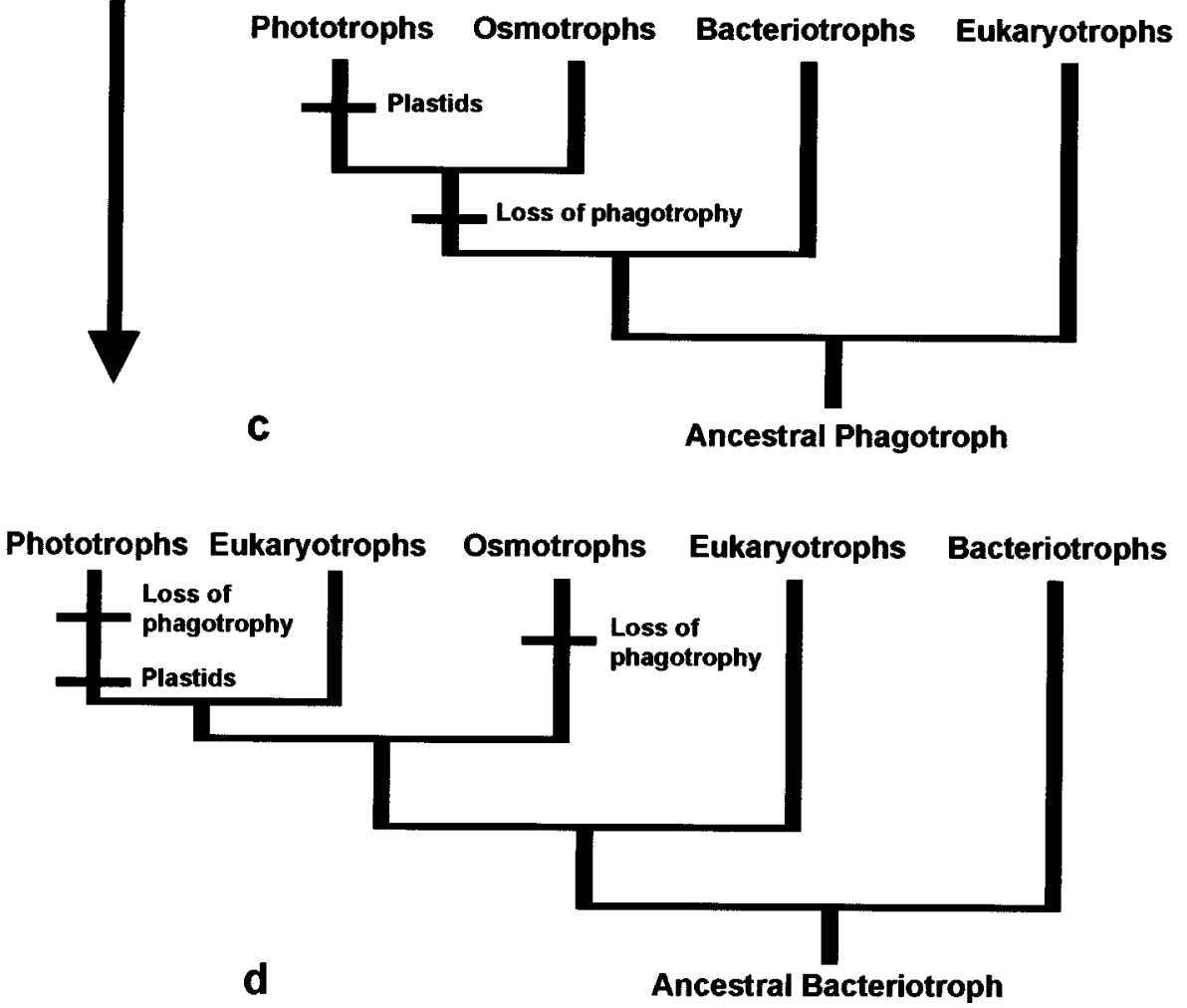
pellicles and crystalline paramylon grains. D inema sulcatum and P. trichophorum possessed two emergent flagella with the ventral flagellum positioned tightly within a specialized pellicular strip designated as the "flagellar strip" (Fig. 5-8). The flagellar strip of P. trichophorum is unique in possessing a significantly broader heel that accommodated the ventral flagellum (Roth 1959; $\mathrm{H}$ ilenski and Walne 1985a)(Fig. 7-8). In D . sulcatum, the flagellar strip was very broad but otherwise similar in morphology to the majority of the strips, particularly those positioned to the right of the flagellar strip (as viewed from the posterior end, Fig. 5-6). In transverse view the flagellar strip appeared to be closely associated with the superficial supporting rod of the feeding apparatus (Fig. 6). The six to seven strips to the left of the flagellar strip (as viewed from the posterior end) possessed a substructure that was more common to euglenids in that the frames were sigmoidal with distinct arches and heels (Fig. 6). The arches were rounded and approximately 3-times the width of the heels. The number of strips around the cell periphery in $D$. sulcatum ranged from $18-22(n=15)$.

The morphology of the canal region in euglenids is diverse. In D. sulcatum, strips surrounded the canal opening but did not extend into the pocket. The anterior portion of the flagellar opening consisted of a vestibulum into which both the flagellar and feeding pockets opened. The flagellar reservoir only formed a complete enclosure well into the cell (Fig. 6). Peranema trichophorum possessed a distinct canal that was internally lined by strips for some of its length ( $\mathrm{N}$ isbet 1974). The canal was also surrounded by supporting elements of unknown composition that did not form a complete ring around the canal (Fig. 9). Split-ringed elements surrounding the canal (syn. scrolls) have al so been observed in R habdomonas and $M$ enoidium (L eedale and $\mathrm{H}$ ibberd 1974) (Fig. 10) and other rhabdomonads (C ann 1986). Similar structures were present around the canal of $D$. proteus. These "peri-canalar fibers" were opaque and slightly smaller in diameter than microtubules (Fig. 11). A Ithough in D. proteus strips did not line the canal lumen, the canalar microtubules and the "pericanalar fibers" served to delineate the canal from the reservoir.

The entire canal of $U$. cyclostomus was lined by pellicle strips and was not supported by splitringed elements (Fig. 12). The number of strips lining the canal, C, was 38-42, which was equivalent to the number of strips surrounding the cell periphery, $P$; therefore, there was no distinct whorl of exponential strip reduction near the anterior end $\left(W_{A}=0\right)$. In addition to having a paraxial rod, the dorsal flagellum of $U$. cyclostomus had a localized, electron-opaque matrix associated with it. This paraflagellar swelling was positioned on the side of the axoneme away from the paraxial rod and in the anterior half of the reservoir (Fig. 13). A separate electron-dense material was associated with a band of sub-reservoir microtubules and positioned in the anterior portion of the reservoir corresponding to that of the paraflagellar swelling (Fig. 13). N either this putative "stigma" nor the paraflagellar swelling was ever detected in the canal.

Fig. 2. Competing hypotheses for the phylogenetic relationships of eukaryotrophic (e.g., D inema and Peranema), bacteriotrophic (e.g., Petalomonas and Ploeotia), osmotrophic (specifically distigmids and rhabdomonads), and phototrophic (e.g., Euglena and Eutreptia) euglenids. The vertical arrow indicates the relative time each hypothesis was proposed. a. L eedale (1967) suggested that the ancestral euglenid was a phototroph that subsequently gave rise to phagotrophs (eukaryotrophs and bacteriotrophs) and osmotrophs by the loss of plastids. b. L eedale (1978) suggested that the ancestral euglenid was an osmotroph (like D istigma) that subsequently gave rise to phagotrophs. Phototrophic euglenids gained plastids from a phagotrophic ancestor through secondary enodsymbiosis. c. Willey and Wibel (1985b) and D awson and Walne (1994) proposed similar hypotheses suggesting that the ancestral euglenid was a phagotroph (whether it was bacteriotrophic or eukaryotrophic was unspecified). Willey and Wibel (1985b) used the absence of feeding rods (syn. nemadesms) to suggest that bacteriotrophs such as Petalomonas and Calycimonas were more closely related to phototrophs than to eukaryotrophs (e.g., Peranema). D awson and Walne (1994) suggested that osmotrophs were descended directly from phagotrophs and indicated graphically that these osmotrophs share a non-phagotrophic (presumably osmotrophic) ancestor with phototrophs. d. In contrast to the previous schemes, the hypothesis outlined in this paper proposes that the ancestral euglenid was a bacteriotroph similar in many ways to Petalomonas. Following the origin of eukaryotrophy, different eukary otrophic lineages are thought to have independently led to osmotrophic and phototrophic modes of nutrition. 


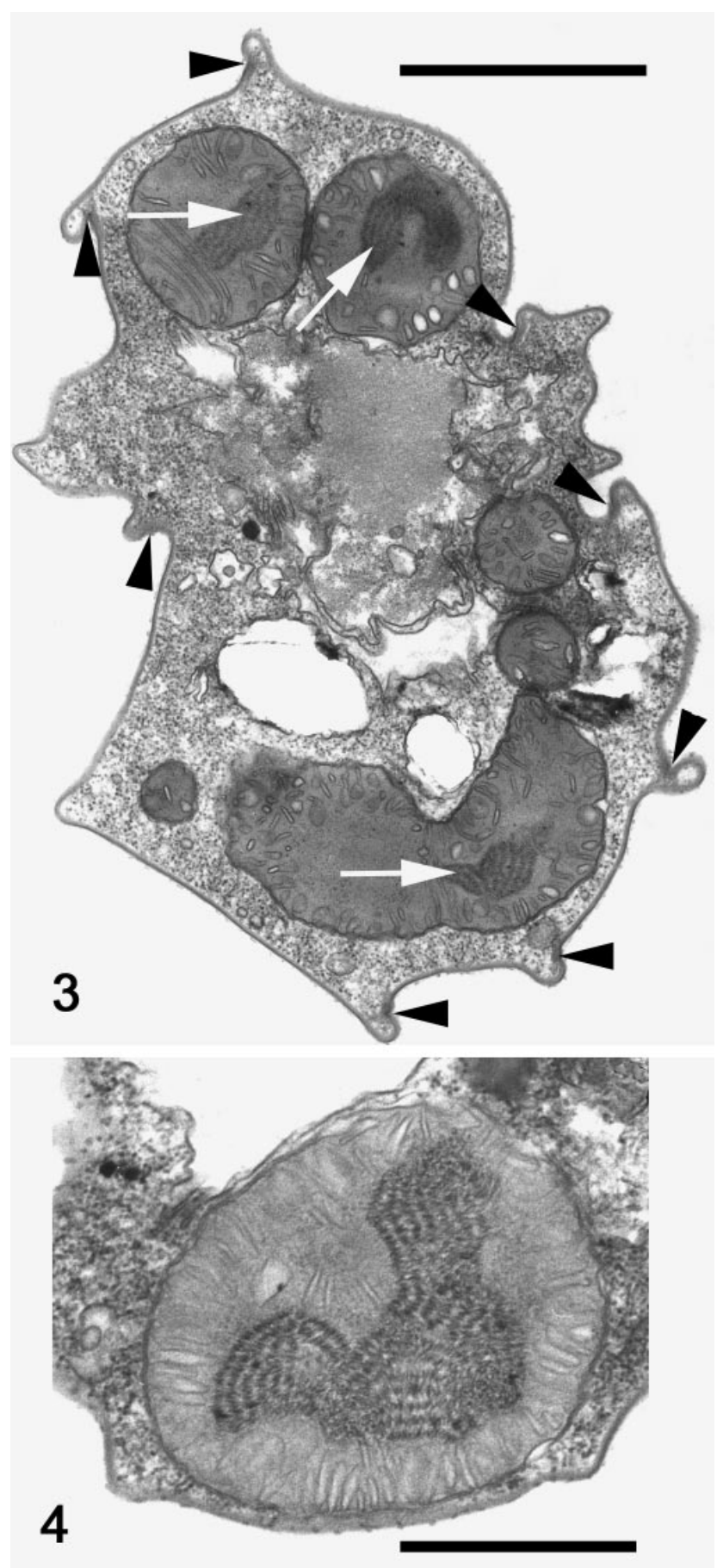

Fig. 3-4. Transmission electron micrographs (TEM) of Petalomonas cantuscygni showing mitochondrial inclusion bodies that resemble kinetoplasts. 3. TEM near the anterior end of the cell showing multiple mitochondrial profiles possessing inclusion bodies (arrows) and pellicle strips. A rrowheads mark the articulation zones (Bar $=1 \mu \mathrm{m})$. 4. A high magnification TEM showing the organized substructure of the inclusion bodies (Bar $=0.25 \mu \mathrm{m}$ ).

\section{Phylogeny of heterotrophic euglenids}

The branch-and-bound analysis produced a single most parsimonious tree (Fig. 14). Petalomonas mediocanellata was the earliest diverging taxon in our ingroup, and the remaining taxa fell within clade $\mathbf{B}$, which represents the Euglenida (i.e., those taxa with pellicle strips). Petalomonas cantuscygni diverged before all other euglenids forming the sister taxon to clade $\mathbf{C}$, which contained two major subclades of heterotrophic euglenids, namely clades $\mathbf{D}$ and I. C lade D consisted of four bacteriotrophic taxa possessing a feeding apparatus of rods and vanes and a resolved internal topology showing $\mathrm{E}$. sulcatum as the sister taxon to a clade containing L entomonas and Ploeotia (clade E, Fig. 14). C lade I consisted of four osmotrophic taxa and an internal topology showing the plastic $D$. proteus as the sister taxon to the rigid rhabdomonads (clade J). The phototrophic euglenids formed a monophyletic group (clade $\mathbf{N}$ ) with an internal topology showing Eutreptia diverging before Euglena. The eukaryotrophs $P$. trichophorum and $U$. cyclostomus clustered with the phototrophs to form clade $\mathbf{L}$, where $U$. cyclostomus was more closely related to the phototrophs than to P. trichophorum (Fig. 14). The eukaryotroph $D$. sulcatum held a pivotal position in the tree in that it bridged the obligate bacteriotrophs with clade $\mathbf{H}$, which was comprised of the other eukaryotrophs, the osmotrophs, and the phototrophs. In general, the cladistic analysis indicated that bacteriotrophs and eukaryotrophs as separate groups are paraphyletic and that osmotrophs sensu stricto and phototrophs as separate groups are monophyletic (Fig. 14).

\section{Discussion}

\section{"Petalomonads" and the origin of euglenids}

The genus Petalomonas as currently defined is paraphyletic. The euglenozoan with the most plesiomorphic character states appears to be P. mediocanellata, which possesses two heterodynamic flagella, a mitochondrial inclusion near the flagellar bases, three asymmetrically arranged flagellar roots, and a phagocytic MTR. It is difficult to identify P. mediocanellata as either a bodonid or a euglenid, in part because it lacks distinct pellicle strips yet possesses the peculiar flagellar beat pattern of phagotrophic euglenids (the dorsal flagellum is held straight and the anterior tip twitches). 
$\mathrm{N}$ onetheless, this taxon has many of the characters that are common to both groups and appears to be an extant form that best represents the most recent common ancestor of bodonids and euglenids.

L ikeP. mediocanellata, the earliest diverging euglenid, P. cantuscygni, possesses mitochondrial inclusion bodies near the flagellar bases that are almost certainly homologous to kinetoplasts. The recognition of kDNA in these inclusion bodies would, of course, eliminate all doubt. N onetheless, from an evolutionary perspective, P. cantuscygni is a prediction come true. By possessing (1) most of the euglenozoan symplesiomorphies, (2) the best synapomorphy for the Euglenida (pellicle strips), and (3) the best synapomorphy for the K inetoplastida (kinetoplasts), this extant taxon succinctly bridges a group containing intracellular parasites (e.g., trypanosomatids) with a group containing
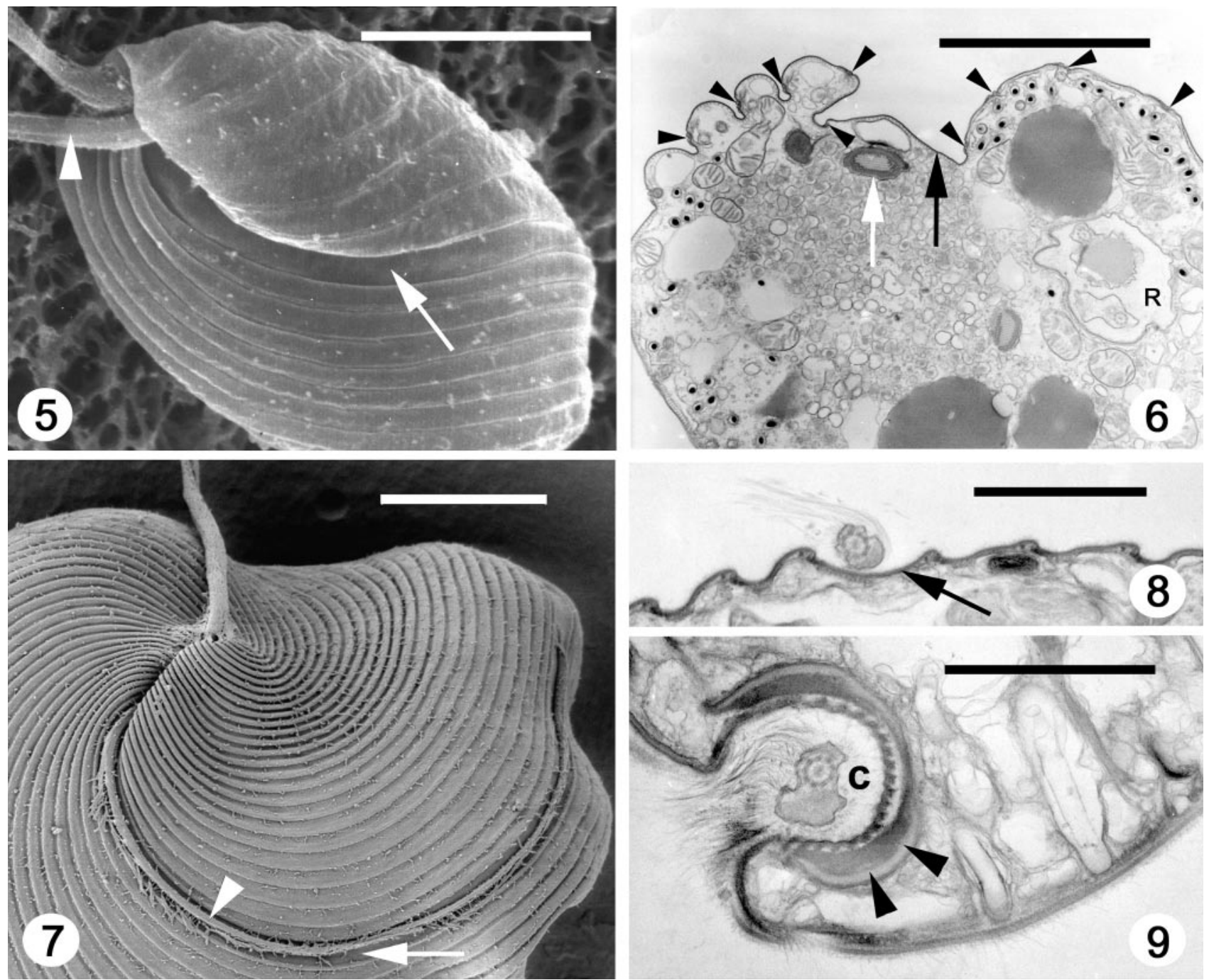

Fig. 5-9. The "flagellar strips" of D inema and Peranema. 5. SE M of D. sulcatum showing the flagellar strip (arrow) and the ventral flagellum (arrowhead) (Bar $=5 \mu \mathrm{m})$. 6. TE M of D. sulcatum showing the flagellar strip (black arrow) and the different morphology of the adjacent strips. A superficial rod of the feeding apparatus (w hite arrow) is in close association with the flagellar strip. The articulation zones between the strips are marked with arrowheads. The strips to the left of the flagellar strip possess distinct heels and rounded arches; the strips to the right of the flagellar strip are flattened as described by L eander and Farmer (2001a). The reservoir (R) is also present (Bar = $3 \mu \mathrm{m})$. 7. SEM of the anterior end of $P$. trichophorum showing the ventral flagellum (arrowhead) running along the flagellar strip (arrow) (Bar =5 $\mu \mathrm{m})$. 8. TE M of P. trichophorum showing the broad heel of the flagellar strip (arrow) (Bar $=1$ $\mu \mathrm{m})$. 9. TEM of $P$. trichophorum showing supporting elements (arrowheads) around the canal (C) (Bar $=1 \mu \mathrm{m})$. 
free-living phototrophs (e.g., euglenophytes). $\mathrm{H}$ owever, this union of character states begs the question: Is P. cantuscygni more closely related to euglenids or kinetoplastids? Phylogenetic analyses of small subunit rDNA using non-euglenozoan outgroups incontrovertibly demonstrate that $P$. cantuscygni forms the sister taxon to the other eu- glenids in the ingroup (M üllner et al. 2001; Preisfeld et al. 2000, 2001). We can infer from these data that the Euglenida was derived from an ancestor possessing kinetoplasts and, consequently, the $\mathrm{K}$ inetoplastida is paraphyletic. Therefore, from a taxonomic point of view, P. cantuscygni is rather problematic.
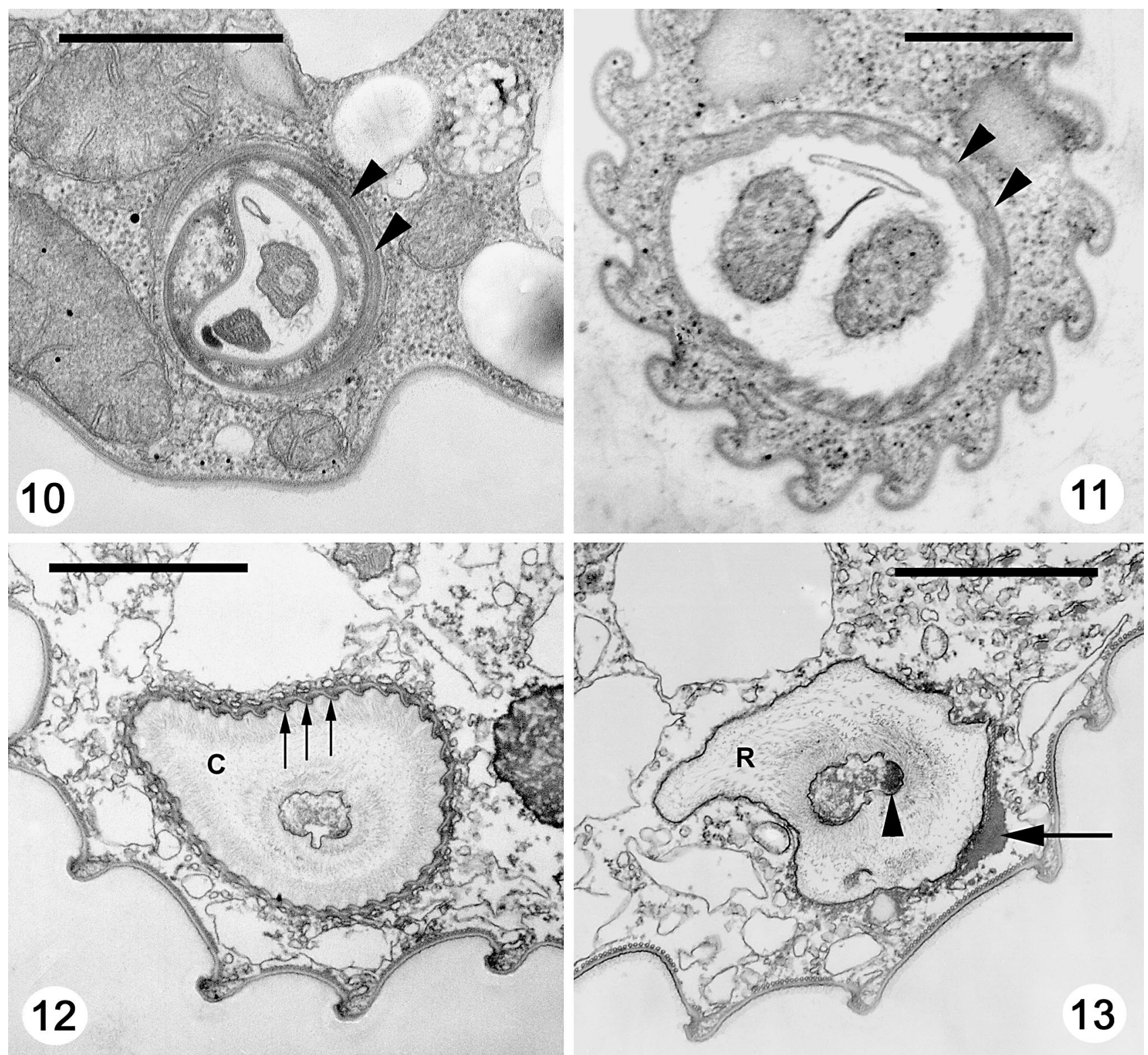

Fig. 10-13. Transverse TEM s comparing the canal morphology of R habdomonas, D istigma, and U rceolus. 10. The canal of R . costata is surrounded by supporting elements called "scrolls" (arrowheads) (L eedale and H ibberd 1974) $(B a r=1 \mu \mathrm{m})$. 11. The canal of $D$. proteus is also surrounded by supporting elements (arrowheads) $(B a r=0.5 \mu \mathrm{m})$. 12. TEM of $U$. cyclostomus showing a canal (C) lined by the same number of strips (arrows) that surround the cell periphery, $P$; in this cell, $P=C=38$. Supporting elements do not surround the canal ( $B a r=1.5 \mu \mathrm{m})$. 13. TEM at the level of the reservoir ( $R$ ) of $U$. cyclostomus (eukaryotroph) showing a paraflagellar sw elling (arrowhead) on the dorsal flagellum and a putative stigma (arrow) $(\mathrm{Bar}=1.5 \mu \mathrm{m})$. 


\section{Ploeotiids and the origin of the feeding apparatus}

Bodonids and petalomonads possess a relatively simple phagocytic M TR, which functions in bacteriotrophy. With the exception of petalomonads, all of the phagotrophic euglenids share a similar type of feeding apparatus consisting of rods and vanes. Rod-like structures have become associated with the M TR in some bodonids (Burzell 1975; Eyden 1977); however, as mentioned previously, these structures are suspected to be analogs of the supporting rods found in euglenids ( $F$ armer and Triemer 1988a; Triemer and O tt 1990; Triemer and
Farmer 1991a). Because the rod-and-vane feeding apparatus is found in so many different taxa, the most parsimonious inference is that rods and vanes appeared fairly early in euglenid evolution; our analysis suggests that they evolved in the most recent common ancestor of clade C (Fig. 14-15). $\mathrm{O}$ ur analysis also indicates that rods supported by relatively few microtubules is a derived state for clade $\mathbf{E}$, and rods supported by many microtubules is homologous in E. sulcatum and the eukaryotrophs (Fig.14-15).

Two unanswered questions remain: (1) Did a rod-and-vane-based feeding apparatus evolve independently of a phagocytic MTR within eu-

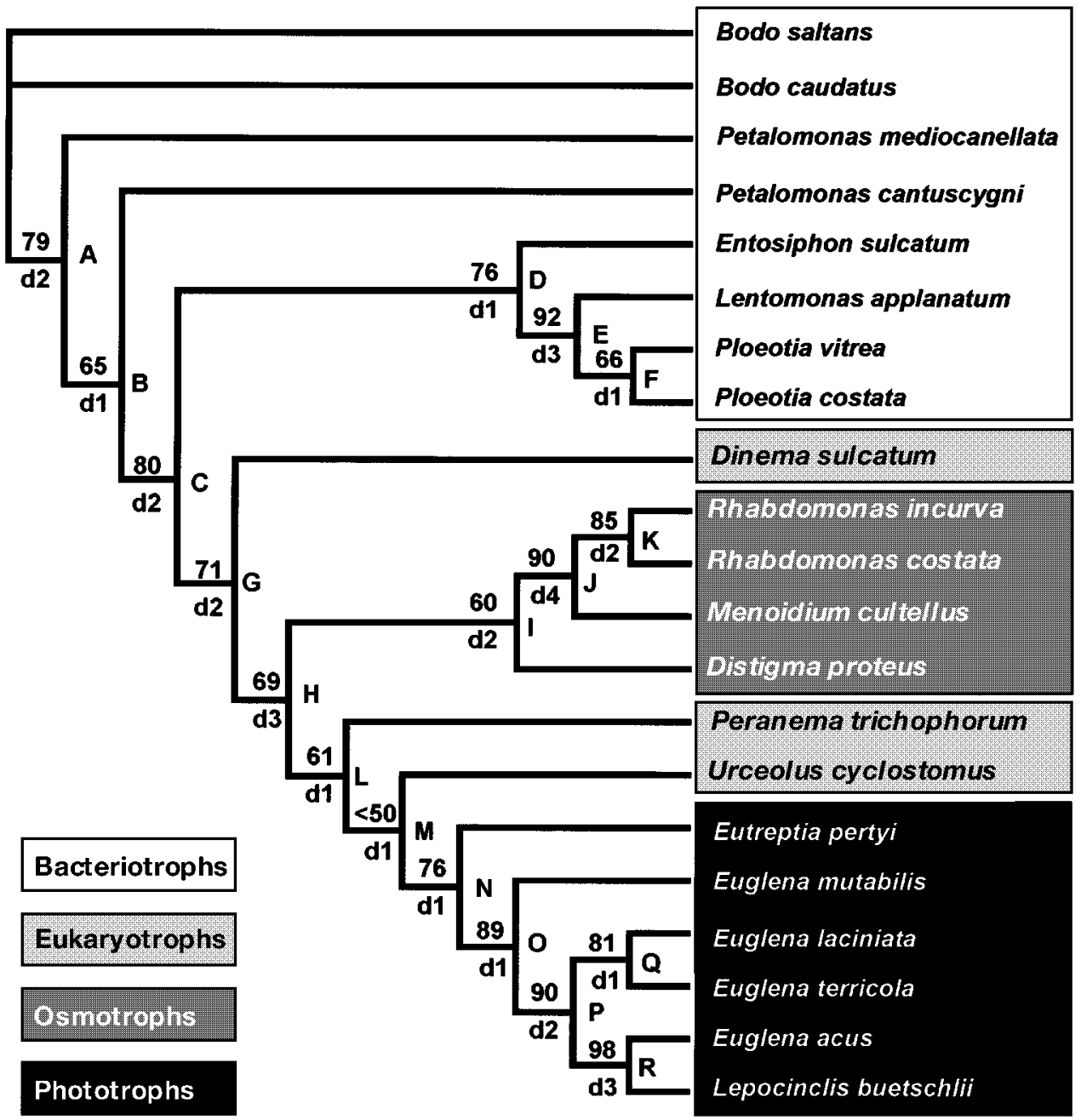

Fig. 14. The single most parsimonious tree using the branch-and-bound algorithm on a matrix of morphological character states from 21 euglenozoan taxa (Tables 2 and 3). A II 37 characters (consisting of 97 states) were unordered and of equal weight. The numbers above the stems are bootstrap percentages from 500 replications; the symbols below each stem represent decay indices. Each clade may be referred to by the letter positioned near the respective node. The consistency index (excluding uninformative characters) was 0.79 and the retention index was 0.90 . C haracter evolution in the nutritional mode of euglenids is indicated. 
glenids and (2) if so, why? Both kinds of feeding apparatus are present in some euglenids (e.g., D inema), where the MTR is assumed either to be vestigial or to function in pinocytosis rather than phagotrophy (Preston 1969; L om et al. 1980). The presence of both kinds of apparatus in the same cell implies that the rod-and-vane based apparatus evolved independently from the M TR. There have been reports that in $C$ alycimonas physaloides and Petalomonas hovassei four vanes exist in the absence of rods (M ignot 1966; K ivic and Walne 1984; Triemer and Farmer 1991b). W hat is not clear is whether the vanes are elaborations of a true M TR or part of a different system al together. R egardless, these taxa may possess important intermediate states for interpreting the evolution of a feeding apparatus of rods and vanes. It is important to note that observations of other members in the genera, namely $C$. robusta and $P$. cantuscygni, possess a distinct MTR without evidence of vanes or rods (Triemer and F armer 1991a, 1991b). The possibility of discovering intermediate states for the feeding apparatus and of resolving some of these inconsistent observations will hopefully inspire further ultrastructural exploration of more phagotrophic euglenids.

\section{Dinema and the origin of the plastic pellicle}

A feeding apparatus of rods and vanes first evolved in obligate bacteriotrophs with rigid pellicles composed of 10-12 longitudinally arranged strips (Fig. 14-16a). In these taxa (clade D) and in Dinema, the rods extend along the entire length of

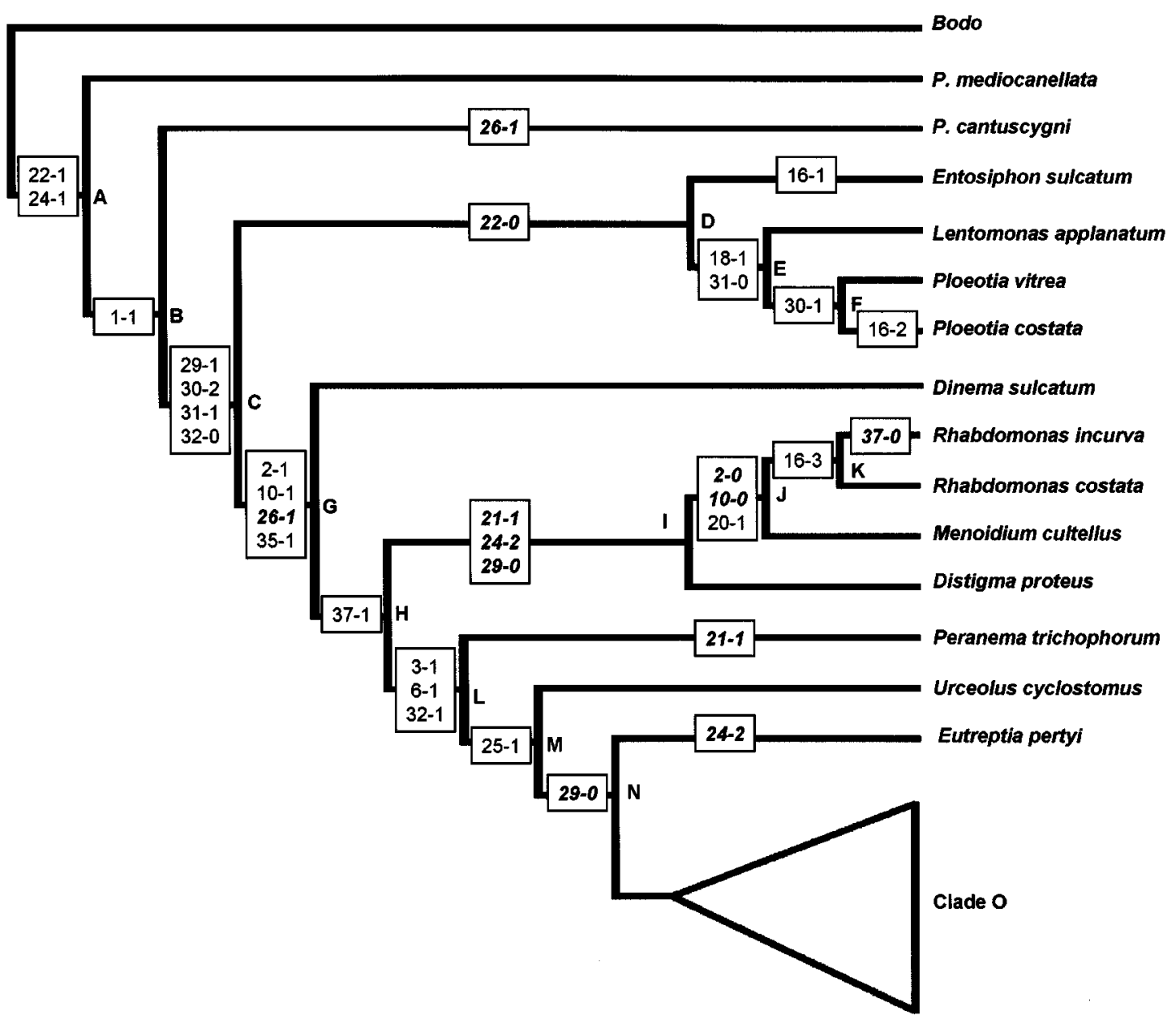

Fig. 15. $M$ any of the morphological character states listed in Table 2 have been parsimoniously mapped onto the tree topology shown in Fig. 14. Two numbers separated by a dash represent each apomorphy; the first refers to the character and the second refers to the respective character state (Tables 2 and 3 ). $\mathrm{H}$ omoplastic character states are shown in bold and italics. L etters correspond to the clades indicated in Fig. 14. 
relatively small cells $(\leq 20 \mu \mathrm{m})$. H owever, a number of key innovations occurred in the most recent common ancestor of clade $\mathbf{G}$ that permitted euglenids to exploit prey much larger and nutritionally richer than bacteria (Fig. 15-16a); these evolutionary events were directly responsible for the origin of eukaryotrophy and, ultimately, phototrophy.

A mong the most significant innovations was a permanent strip duplication event, where $P$ jumped from around 10 to 20 (Fig. 16a). The stripdoubling event was likely to have been the result of a cell that duplicated its cytoskeleton without ever undergoing cytokinesis (L eander and $\mathrm{F}$ armer 2001b). There were two important cytoskeletal consequences from this duplication event: (1) twice the number of articulation zones between strips was produced and (2) the strips became heli- cally arranged. "Sliding" of adjacent strips at the articulation zones has been shown to facilitate euglenoid movement (G allo and Schrével 1982; Suzaki and Williamson 1985, 1986). Consequently, an increase in the number of articulation zones generated a less constrained pellicle and an increased ability for changing cell shape. The length and substructural morphology of strips has been shown to remain constant during euglenoid movement (Suzaki and Williamson 1985, 1986). Therefore, in order for contractions in cell shape to occur, it is physically necessary that the strips become helically arranged. The gain of pellicle plasticity is inferred to be physically necessary for the engulfment of eukaryotic prey.

A the time eukaryotrophy became established, a beta- 1,3 glucan storage product in the form of
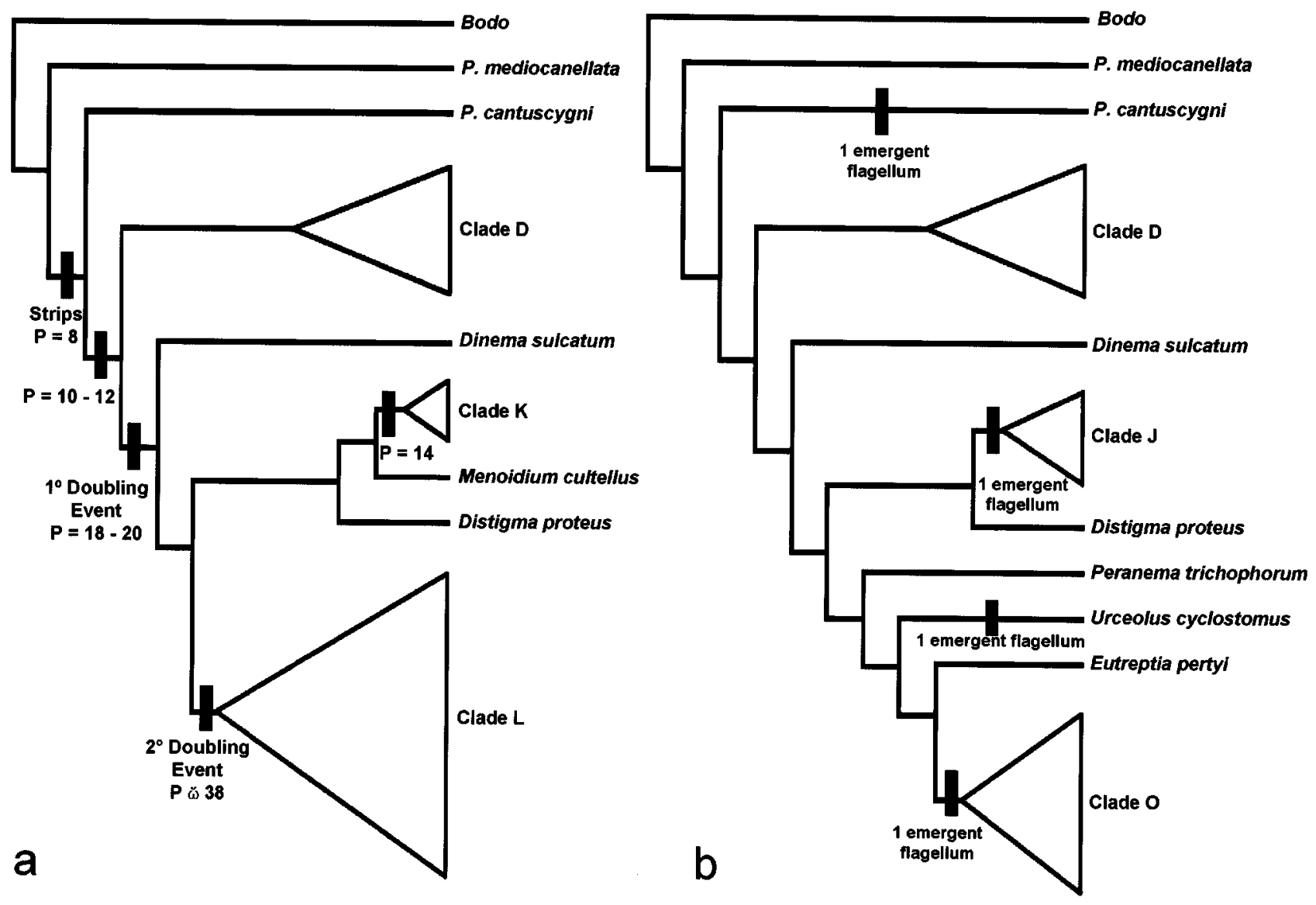

Fig. 16. Two specific examples of character evolution within the heterotrophic euglenids. a. Illustration showing the evolution of "P", the maximum number of strips around the cell periphery. The ancestral state for $P=8-12$ and subsequently doubled to $P=18-20$. A second strip-doubling event, where $P$ jumped from 20 to about 40 , occurred prior to the ancestor of clade $\mathbf{L}$. R eduction in the number of strips evolved convergently in the ancestor of clade $\mathbf{K}$ $(P=14)$ and within clade $\mathbf{L}$ (L eander and Farmer 2001b). b. Illustration showing convergent evolution in the number of emergent flagella. A Il taxa possess two emergent flagella except where indicated. L etters correspond to the clades in Fig. 14. 
paramylon grains emerged that has been retained in all taxa of clade $\mathbf{G}$ (Fig. 14). There are no confirmed reports of paramylon in kinetoplastids or the phagotrophic euglenids that diverge prior to clade G. Beta-1, 3 glucans are usually found in groups of phototrophic eukaryotes such as dinoflagellates, chrysophytes, and haptophytes (L eedale 1967; Kivic and Walne 1984; K iss et al. $1987,1988)$. Both the eukaryotrophic ancestry and exclusive presence of paramylon in clade $\mathbf{G}$ feeds speculation that the paramylon grains of euglenids were derived from non-chlorophyte phototrophic prey. If this did occur, then presumably the genetic machinery necessary for maintaining paramylon grains was transferred from the prey to the host's genome.

A $n$ apparent trend in euglenid evolution is the tendency for fairly obvious structures to become independently lost multiple times. This appears to have happened to (1) the feeding apparatus of rods
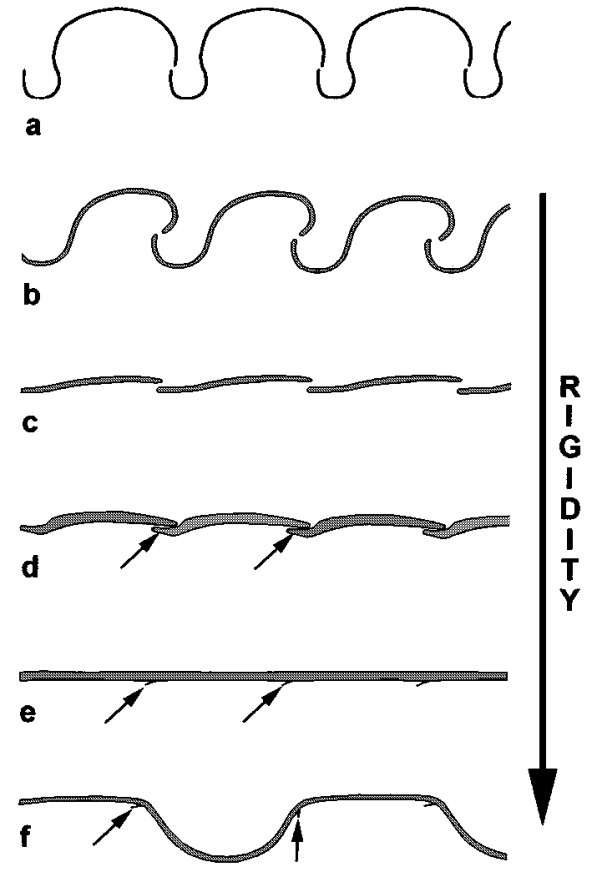

Fig. 17. $\mathrm{H}$ ypothetical scenario for the evolution of strips within clade I (Fig. 14); see text for discussion. a. Dinema sulcatum; illustration represents those strips positioned to the left of the flagellar strip as viewed from the posterior end (Fig. 6). b. Distigma proteus. C. $D$ istigma curvatum (A ngeler et al. 1999). d. D istigma elegans and D. sennii (A ngeler et al. 1999). e. M enoidium cultellus. f. R habdomonas costata and R. incurva. A rrows indicate homologous heel-like structures marking the articulation zones between fused strips. and vanes within clade $\mathbf{C},(2)$ chloroplasts within clade $\mathbf{N},(3)$ an emergent ventral flagellum within clade B (Fig. 16b), and (4) the flagellar strip within clade G (Fig. 14-15). A ccordingly, it would be poor taxonomic practice to group euglenid taxa based on the absence of any of these features. We suspect that the ancestor of clade $\mathbf{G}$ possessed a distinct flagellar strip, like those found in D inema and Peranema (Roth 1959; H ilenski and Walne 1985a) (Fig. 5-8), that was lost independently in the ancestors of clades I and $\mathbf{M}$. The flagellar strips of these eukaryotrophs may be homologous to a strip on the distinct ventral surface of pellicles found in clade E (Fig. 14) (Triemer 1986; F armer and Triemer 1988b, 1994) and perhaps also to the ventral grooves of some bodonids. The flagellar strip may be an important marker for following the ontogenetic and phylogenetic development of the euglenid cytoskeleton. There might be a permanent association between the ventral flagellum and the flagellar strip that can be traced in all lineages of euglenids. Identification of this specialized strip in various taxa may help delineate strips resulting from early evolutionary events (e.g., permanent strip duplication events) from those derived from relatively late events (Leander and Farmer 2001b).

\section{Rhabdomonads and distigmids have a eukaryotrophic ancestry}

Based primarily on the split-ringed elements or "scrolls" surrounding the canal and the absence of a feeding apparatus, L eedale and $\mathrm{H}$ ibberd (1974) proposed the "R habdomonadales". Subsequent investigation by $C$ ann (1986) showed that taxa other than Rhabdomonas and M enoidium (e.g., Gyropaine, Parmidium, and $\mathrm{R}$ habdospira) also possess the unusual supporting elements around the canal. R habdomonads also possess rigid pellicles with fused strips that are often arranged longitudinally (Fig. Id-e); this presents the possibility that the group is derived directly from rigid bacteriotrophs such as Ploeotia and E ntosiphon.

H ow ever, we have demonstrated that D. proteus also possesses split-ringed structures around the canal (Fig. 11) despite previous ultrastructural studies that did not report the presence of these structures (Yamaguchi and A nderson 1994; A ngeler et al. 1999). M oreover, our cladistic analysis of morphological characters grouped Distigma with the rhabdomonads (Fig. 11 and 14), which is con- 
sistent with the finding of M üllner et al. (2001) and Preisfeld et al. (2001) using small subunit rD N A sequences. Clade I was rather surprisingly derived from within the eukaryotrophs (Fig. 14). Because distigmids are capable of intense euglenoid movement, which originated in the ancestor of clade $\mathbf{G}$ (Fig. 14-15), we can more confidently infer that rhabdomonads were derived from plastic, eukaryotrophic ancestors. We did not find any additional evidence, however, suggesting that the scrolls around the canal were derived from a feeding apparatus of rods and vanes (L eedale and $\mathrm{H}$ ibberd 1974; L eedale 1978).

In the context of this new insight, we can amend the scenario for the evolution of strip substructure presented by Leander and Farmer (2001a) (Fig. 17). We infer that sigmoidal strips like those found in $D$. proteus became increasingly flattened so that the arch and heel became more or less indistinguishable as in D. curvatum (A ngeler et al. 1999) (Fig. 17). The frames began to thicken leaving a thin hook-like region that extended prearticularly beneath the overhang of an adjacent strip as in $D$. elegans and D . sennii (A ngeler et al. 1999). We suspect that these hook-like regions are homologous to the delicate structures marking the fused articulation zones (syn. discontinuities, L eedale and $\mathrm{H} \mathrm{i-}$ bberd 1974) of M enoidium and R habdomonas ( $L$ eander and Farmer 2001a) (Fig. 17). The peculiar strip doublets of $\mathrm{R}$ habdomonas and the completely fused strips of Parmidium and $G$ yropaine ( $C$ ann 1986) are inferred to have evolved independently from strips similar to M enoidium.

The number of emergent flagella changed from two to one during the evolution of rhabdomonads from the ancestor of clade $\mathbf{H}$ (Fig. 16b). D istigma proteus possesses two emergent flagella, but the rather short ventral flagellum may indicate an intermediate step toward a single emergent flagellum. Moreover, there are several taxa currently classified as Astasia that are most likely distigmids with a single emergent flagellum (e.g., A. edax and A. concinna, Christen 1959; A. tortuosa, A ngeler 1998; A. comma and A. curvata, Müllner et al. 2001). If these taxa are truly misplaced as small subunit rD N A sequences suggest ( $M$ üllner et al. 2001), then they provide additional intermediate states between the biflagellated distigmids and the uniflagellated rhabdomonads. D etailed analy ses of the pellicle of these "A stasia" taxa, particularly the value of $P$ (the number of strip around the cell periphery) and $W_{p}$ (the number of whorls of strip re- duction), will more confidently demonstrate their relationship to distigmids (A ngeler 1998; A ngeler et al. 1999; L eander and F armer 2000a); distigmids possess $P=18-20$ and $W_{P}=0$, whereas A stasia (e.g., A. longa) possesses $P=40$ and $W_{P}=3$ (L eander and Farmer 2000a).

The idea that D istigma, Eutreptia, and Eutreptiella should be classified together within an order "E utreptiales" is inconsistent with both molecular and morphological data (M üllner et al. 2001; Preisfeld et al. 2001) (Fig. 14). A new taxon name should probably be erected that encompasses true distigmids with the rhabdomonads. This group may be diagnosed as possessing split-ringed elements around the canal (scrolls), $\mathrm{P}=18, \mathrm{~W}_{\mathrm{P}}=0$, osmotrophy, and a dorsal flagellum with a highly mobile beat pattern. It is currently unclear whether the supporting elements around the canal of $P$. trichophorum (Fig. 9) are homologous with the scrolls of distigmids and rhabdomonads; we have mapped them as being analogs (Fig. 15), but the origin of scrolls in the ancestor of clade $\mathbf{H}$ and their subsequent loss in clade $\mathbf{M}$ is an equally parsimonious scenario.

\section{Urceolus cyclostomus and the origin of phototrophs}

A number of key evolutionary innovations occurred in the ancestor of clade $\mathbf{L}$ that set the stage for the endosymbiotic origin of phototrophy in euglenids (Fig. 14-15). The most significant of which was a second permanent strip duplication event that increased the number of strips around the cell periphery from 20 to about 40 (Fig. 16a). A ssociated with this event were increases in the cell size ( $\geq 20 \mu \mathrm{m})$ and the number of articulation zones. The rods of the feeding apparatus became localized to the anterior portion of the cell, where the length of the rods was less than 1/2 the length of the cell. The phagotrophic taxa within clade $\mathbf{L}$ became voracious predators of diverse eukaryotic prey, including phototrophic euglenids (Triemer 1997).

A nother important correlation to the second strip duplication event was the reinforcement of the canal by strips. $C$ anals lined by strips have only been found in taxa within clade $\mathbf{L}$ (Fig. 14-15). In most phototrophs, the number of strips surrounding the canal lumen, $C$, is half the number around the cell periphery, $P$ (Leander and Farmer 2000a, 2000b, 2001b). In P. trichophorum and U . cyclosto- 
mus, $\mathrm{P}$ was equivalent to $\mathrm{C}$ ( $\mathrm{Fig}$. 12). A the posterior end of phototrophs, terminating strips are organized as distinct whorls (Leander and Farmer 2000a, 2000b, 2001b). Patterns of strip reduction are al so present at the posterior end of P. trichophorum (L eander and Farmer 2001b) and U . cyclostomus, however the current absence of SEM data makes the exact organization of terminating strips on $\mathrm{U}$. cyclostomus indeterminable. $\mathrm{N}$ onetheless, the presence of strips around the canal, the presence of $P \geq 38$, and the presence of posterior strip reduction are important cytoskeletal evidence linking the phototrophs to eukaryotrophic ancestors.

Because phototrophs are the only euglenids known to possess a photoreception apparatus, perhaps the most significant discovery linking the phototrophs to eukaryotrophs is the presence of a presumptive paraflagellar swelling and stigma in U. cyclostomus (Fig. 13). Presumably, the stigma and paraflagellar swelling of $U$. cyclostomus function together in photoreception in much the same way these structures function in phototrophs (Robenek and Melkonian 1983; K uźnicki et al. 1990). It has been generally argued that a photoreception apparatus should logically develop after the acquisition of plastids because the necessity for the new photosynthetic host to find optimal light would become a strong selective pressure (K ivic and Walne 1983). H ow ever, the possession of both a feeding apparatus of rods and vanes and a photoreception apparatus within the same euglenid cell may be explained by one of three alternative scenarios: (1) the apparatus in U . cyclostomusis not homologous to the photoreception apparatus in phototrophs, (2) the photoreception apparatus evolved after or at the same time as plastids, but plastids have subsequently been lost in $\mathrm{U}$. cyclostomus, or (3) the photoreception apparatus evolved before the origin of plastids and is homologous in all euglenids that possess one.

0 ur cladistic analysis and the identical structure and cellular position of the apparatus (e.g., not associated with the plastid as in most other groups of algae) in both $U$. cyclostomus and phototrophs rules out the first scenario. The fact that $U$. cyclostomus lacks any evidence of a plastid, possesses a feeding apparatus of rods and vanes and actively engages in eukaryotrophy seems to rule out scenario two. The third scenario implies that a eukaryotroph benefited from the capability of photoreception. The most obvious advantage is that eukaryotrophs capable of photoreception (e.g., phototaxis) would have an increased ability to position themselves in an environment with abundant phototrophic prey. It makes perfect sense, then, that the first eukaryotrophic euglenid to consume and subsequently foster an endosymbiotic relationship with green algal plastids already possessed the photoreception apparatus. The presence of the apparatus in the host may have actually increased the likelihood that the endosymbiosis would ultimately succeed. N onetheless, it is still unclear whether the stigma of $U$. cycl ostomus originated autogenously or was derived from an independent endosymbiotic event that occurred before plastid acquisition.

M enoidium and Peranema have "layered material" near the base of the dorsal flagellum that coincides with the position of the paraflagellar swelling in other taxa ( $\mathrm{L}$ eedale and $\mathrm{H}$ ibberd 1974; $\mathrm{H}$ ilenski and Walne 1985b). Leedale and H ibberd (1974) suggested that this material might be evidence of a vestigial photosensory swelling indicating that rhabdomonads were derived from phototrophs. The layered material is positioned on the same side of the flagellum as the paraxial rod, and the distinction between the two structures is extremely subtle. We infer that the layered material of M enoidium and Peranema is not homologous to the paraflagellar swelling of $U$. cyclostomus because the latter is significantly more electron dense (like those in phototrophs) and positioned on the opposite side of the paraxial rod. H owever, if the layered material is homologous to paraflagellar swellings, than we would argue based on our cladistic analysis that the material represents an intermediate state in the evolution of photosensory swellings and does not represent a vestige of phototrophic ancestry.

Acknowledgements: This work was supported by the $\mathrm{N}$ ational Science Foundation PEET (Partnerships for the Enhancing Expertise in Taxonomy, grant no. DEB 4-21348).

\section{References}

A ngeler D . G ., M üllner A . N . and Schagerl M . (1999): C omparative ultrastructure of the cytoskeleton and nucleus of D istigma (E uglenozoa). E urop. J. Protistol. 35, 309-318.

A ngeler D. G . (1998): Zur systematischen stellung von A stasia tortuosa (Stokes) Popova, inkl. A . tortuosa var. harrisii (E. G. Pringsheim) A ngeler stat. nov. (E uglenophyta). Phyton 39, 27-35. 
Belhadri A . and Brugerolle G. (1992): M orphogenesis of the feeding apparatus of Entosiphon sulcatum: An immunofluorescence and ultrastructural study. Protoplasma $168,125-135$.

Belhadri A., Bayle D . and Brugerolle G . (1992): Biochemical and immunological characterization of intermicrotubular cement in the feeding apparatus of phagotrophic euglenoids: Entosiphon, Peranema, and Ploeotia. Protoplasma 168, 113-124.

Brooker B. E. (1971): Fine structure of Bodo saltans and Bodo caudatus (Zoomastigophora: Protozoa) and their affinities with the trypanosomatidae. Bull. Br. Mus. nat. $\mathrm{H}$ ist. (Zool.) 22, 89-115.

Brugerolle G., L om J., N ohynkova E. and Joyon L. (1979): Comparison et évolution des structures cellulaires chez plusiers espèces de Bodonidés et Cryptobiidés appartenant\#aux genres Bodo, Cryptobia et Trypanoplasma (K inetoplastida, Mastigophora). Protistologica 15, 197-221.

Burzell L . A . (1975): Fine structure of B odo curvifilus G riessmann (K inetoplastida: Bodonidae). J. Protozool. 22, 35-39.

C ann J. P. (1986): U Itrastructural observations of taxonomic importance on the euglenoid genera G yropaine Skuja, Parmidium Christen and Rhabdospira Pringsheim (E Uglenida: Rhabdomonadina). A rch. Protistenkd. 132, 395-401.

Cann J. P. and Pennick N. C. (1986): O bservations on Petalomonas cantuscygni, n. sp., a new halo-tolerant strain. A rch Protistenkd. 132, 63-71.

Christen H . R . (1959): N ew colorless Eugleninae. J. Protozool. 6, 292-303.

D awson N . S. and Walne P. L. (1994): Evolutionary trends in euglenoids. A rch. Protistenkd. 144, 221-225.

Eriksson T. (1998): A utoD ecay ver. 4.0 (program distributed by the author). Bergius Foundation, Royal Swedish A cademy of Sciences, Stockholm.

Eyden B. P. (1977): Morphology and ultrastructure of Bodo designis Skuja 1948. Protistologica 13, 169-179.

Farmer M . A . and Triemer R. E . (1988a): Flagellar systems in the euglenoid flagellates. BioSystems 21, 283-291.

Farmer M. A . and Triemer R. E. (1988b): A redescription of the genus Ploeotia Duj. (Euglenophyceae). Taxon 37, 319-325.

Farmer M. A . and Triemer R. E. (1994): A n ultrastructural study of Lentomonas applanatum (Preisig) N. G. (Euglenida). J. Eukaryot. M icrobiol. 41, 112-119.

Felsenstein J. (1985): C onfidence limits on phylogenies: an approach using the bootstrap. E volution 39, 783-791.

Gallo J. M . and Schrével J. (1982): Euglenoid movement in D istigma proteus, I - C ortical rotational motion. Biol. C ell 44, 139-148.

Gibbs S. P. (1978): The chloroplasts of Euglena may have evolved from symbiotic green algae. Can. J. Bot. 56, 2883-2889.

G ibbs S. P. (1981): The chloroplasts of some al gal groups may have evolved from endosymbiotic eukaryotic algae. A nn. N. Y. A cad. Sci. 361, 193-208.

G ockel G. and H achtel W. (2000): C omplete gene map of the plastid genome of the nonphotosynthetic euglenoid flagellate A stasia longa. Protist 151, 347-351.

G reenblatt C. L. and Schiff J. A. (1959): A pheophytin-like pigment in dark-adapted Euglena gracilis. J. Protozool. 6, 23-28.
H ilenski L . L . and Walne P. L. (1985a): U Itrastructure of the flagella of the colorless phagotroph Peranema trichophorum (E uglenophyceae). I. Flagellar mastigonemes. J. Phycol. 21, 114- 125 .

H ilenski L. L. and Walne P. L . (1985b): U Itrastructure of the flagella of the colorless phagotroph Peranema trichophorum (E uglenophyceae). II. Flagellar roots. J. Phycol. 21, 125-134.

$H$ itchen E. T. (1974): The fine structure of the colonial kinetoplastid flagellate Cephalothamnium cyclopum Stein. J. Protozool. 21, 221-231.

K iss J. Z., Vasconcelos A. C. and Triemer R. E. (1987): Structure of the euglenoid storage product, paramylon. A m. J. Bot. 74, 877-882.

K iss J . Z., Vasconcel os A . C . and Triemer R. E . (1988): The intermembranous particle profile of the paramylon grain during paramylon synthesis in Euglena (Euglenophyceaea). J. Phycol. 24, 152-157.

K ivic P. A . and Walne P. L. (1983): A Igal photosensory apparatus probably represent multiple parallel evolutions. BioSystems 16, 31-38.

Kivic P. A . and Walne P. L. (1984): A n evaluation of a possible phylogenetic relationship between the Euglenophyta and $K$ inetoplastida. O rigins of L ife 13, 269-288.

K uźnicki L., M ikolajczyk E . and WalneP. L. (1990): Photobehavior of euglenoid flagellates: Theoretical and evolutionary perspectives. CR C C rit. R ev. Plant Sci. 9, 343-369.

L eander B. S. and Farmer M . A . (2000a): C omparative morphology of the euglenid pellicle. I. Patterns of strips and pores. J. Eukaryot. M icrobiol. 47, 469-479.

L eander B. S. and Farmer M. A. (2000b): E pibiotic bacteria and a novel pattern of strip reduction on the pellicle of $E u$ glena helicoideus (Bernard) L emmermann. Europ. J. Protistol. 36, 405-413.

Leander B. S. and Farmer M. A. (2001a): The evolution of Phacus (E uglenozoa) as inferred from pellicle morphology and SSU rD N A. J. Phycol. 37, 1-17.

L eander B. S. and Farmer M . A . (2001b): C omparative morphology of the euglenid pellicle. II. D iversity of strip substructure. J. Eukaryot. Microbiol. 48, 204-219.

L eedale G. F. (1967): Euglenoid Flagellates. Prentice H all, Englew ood Cliffs, N J. Pp. 1-224.

L eedale G . F. (1978): Phylogenetic criteria in euglenoid flagellates. BioSystems 10, 183-187.

L eedale G . F. and H ibberd D. J. (1974): O bservations on the cytology and fine structure of the euglenoid genera Menoidium Perty and Rhabdomonas Fresenius. A rch. Protistenkd. 116, 319-345.

Linton E. W., N udelman A., C onforti V. and Triemer R. E . (2000): A molecular analysis of the genus Euglena (Euglenophyta) using SSU rD N A. J. Phycol. 36, 740-746.

Linton E. W. and Triemer R. E. (1999): Reconstruction of the feeding apparatus in Ploeotia costata (E uglenophyta) and its relationship to other euglenoid feeding apparatuses. J. Phycol. 35, 313-324.

Linton E. W. and Triemer R. E. (2001): Reconstruction of the flagellar apparatus in Ploeotia costata (E uglenozoa) and its relationship to other euglenoid flagellar apparatuses. J. Eukaryot. M icrobiol. 48, 88-94.

Lom J., Paulin J. J. and N ohynkova E. (1980): The fine structure of the fish trypanosome, Trypanosoma danilewskyi: I . Presence of a cytopharyngeal complex in bloodstream trypanomastigotes. Protistologica 16, 365-373. 
Mignot, J. P. (1966): Structure et ultrastructure de quelques euglenomonadines. Protistologica 2, 51-140.

Montegut-F elkner A . E . and Triemer R. E. (1997): Phylogenetic relationships of selected euglenoid genera based on morphological and molecular data. J. Phycol. 33, 512-519.

M üllner A . N ., A ngeler D. G., Samuel R., Linton E. W. and Triemer R. E. (2001): Phylogenetic analysis of phagotrophic, phototrophic and osmotrophic euglenoids by using nuclear $18 \mathrm{~S}$ rD N A sequences. Int. J. Syst. E vol. M icrobiol. 51, 783-791.

$\mathrm{N}$ isbet B. 1974. A n ultrastructural study of the feeding apparatus of Peranema trichophorum. J. Protozool. 21, 39-48.

O wens K . ., F armer M . A . and Triemer R. E. (1988): Theflagellar apparatus and reservoir/canal cytoskeleton of C ryptoglena pigra (E ugleno phyceae). J. Phycol. 24, 520-528.

Preisfeld A., Berger S., Busse I., Liller S. and Ruppel H. G. (2000): Phylogenetic analysis of various euglenoid taxa (Euglenozoa) based on 18S rD N A sequence data. J. Phycol. 36, 220-226.

Preisfeld A., Busse I., K lingberg M., Talke S. and R uppel H . G . (2001): Phylogenetic position and inter-relationships of the osmotrophic euglenids based on SSU rDNA data, with emphasis on the Rhabdomonadales (Euglenozoa). Int. J. Syst. Evol. M icrobiol. 51, 751-758.

Preston T. M. (1969): The form and function of the cytostome-cytopharynx of the culture forms of the elasmobranch haemoflagellate Trypanosoma raiae $L$ averan and M esnil. J. Protozool. 16, 320-333.

Robenek H. and M elkonian M . (1983): Structural specialization of the paraflagellar body membrane of E uglena. Protoplasma 117, 154-157.

Roth L. E. (1959): A n electron-microscope study of the cytology of the protozoan Peranema trichophorum. 6, 107-116.

Simpson A . G . B. (1997): The identity and composition of the euglenozoa. A rch. Protistenkd. 148, 318-328.

Solomon J. A ., Walne P. L. and K ivic P. A . (1987): Entosiphon sulcatum (Euglenophyceae): Flagellar Roots of the basal body complex and reservoir region. J. Phycol. 23, 85-98.

Starr R. C . and Zeikus J. A . (1993): U TEX -The Culture C ollection of A lgae at the U niversity of Texas at A ustin, 1993 List of C ultures. J. Phycol. 29, 1-106.

Surek B. and M elkonian M. (1986): A cryptic cytostome is present in E uglena. Protoplasma 133, 39-49.

Suzaki T. and Williamson R. E. (1985): Euglenoid movement in Euglena fusca: evidence for sliding between pellicular strips. Protoplasma 124, 137-146.

Suzaki T. and Williamson R. E. (1986): U Itrastructure and sliding of pellicular structures during euglenoid move- ment in Astasia longa Pringsheim (Sarcomastigophora, Euglenida). J. Protozool. 33, 179-184.

Swofford D. L. (1999): PA U P*: Phylogenetic analysis using parsimony (and other methods), version 4.0 Sinauer A ssociates, Sunderland, M A.

Triemer R. E. (1995): U Itrastructural features of mitosis in A nisonema sp. (E uglenida). J. Protozool. 32, 683-690.

Triemer R. E . (1986): Light and electron microscopic description of a colorless euglenoid, Serpenomonas costata n. g., n. sp. J. Protozool. 33, 412-415.

Triemer R. E . (1988): U Itrastructure of mitosis in Entosiphon sulcatum (Euglenida). J. Protozool. 35, 231-237.

Triemer R . E . (1997): Feeding in Peranema trichophorum Revisited (E uglenophyta). J. Phycol. 33, 649-654.

Triemer R. E. and Farmer M. A. (1991a): A n ultrastructural comparison of the mitotic apparatus, feeding apparatus, flagellar apparatus and cytoskeleton in euglenoids and kinetoplastids. Protoplasma 164, 91-104.

Triemer R. E . and Farmer M. A . (1991b): The ultrastructural organization of the heterotrophic euglenids and its evolutionary implications. In: Patterson D. J. and Larsen J. (eds.): The biology of free-living heterotrophic flagellates, pp. 205-217. Clarendon Press, O xford.

Triemer R. E . and Fritz L. (1987): Structure and operation of the feeding apparatus in a colorless euglenoid, Entosiphon sulcatum. J. Protozool. 34, 39-47.

Triemer R. E. and Fritz L . (1988): U Itrastructural features of mitosis in Ploeotia costata (H eteronematales, Euglenophyta). J. Phycol. 24, 514-519.

Triemer R. E . and O tt D. W. (1990): U Itrastructure of D iplonema ambulator $L$ arsen and Patterson (Euglenozoa) and its relationship to I sonema. E ur. J. Protistol. 25, 316-320.

Vickerman K. (1991): O rganization of the bodonid flagellates. In: Patterson D. J. and Larsen J. (eds.): The biology of free-living heterotrophic flagellates, pp. 159-176. Clarendon Press, 0 xford.

Willey R. L., Walne P. L . and K ivic P. (1988): Phagotrophy and the origins of the euglenoid flagellates. CRC C rit. Rev. Plant Sci. 7, 303-340.

Willey R . L . and Wibel R. G . (1985a): The reservoir cytoskeleton and a possible cytostomal homologue in Colacium (E uglenophyceaea). J. Phycol. 21, 570-579.

Willey R. L. and W ibel R. G . (1985b): A cytostome/cytophar$y n x$ in green euglenoid flagellates (E uglenales) and its phylogenetic implications. BioSystems 18, 369-376.

Yamaguchi T. and Anderson O . R. (1994): Fine structure of laboratory cultured Distigma proteus and cytochemical localization of acid phosphatase. J. M orphol. 219, 89-99. 